\title{
Adipose tissue remodeling in late-lactation dairy cows during feed-restriction-induced negative energy balance
}

\author{
G. Andres Contreras, ${ }^{* 1}$ Kyan Thelen, ${ }^{*}$ Sarah E. Schmidt, $\dagger$ Clarissa Strieder-Barboza, ${ }^{*}$ Courtney L. Preseault, $\dagger$ \\ William Raphael, ${ }^{*}$ Matti Kiupel, $\ddagger$ John Caron, ${ }^{*}$ and Adam L. Lock† \\ *Department of Large Animal Clinical Sciences, \\ †Department of Animal Science, and \\ ‡Department of Pathobiology and Diagnostic Investigation, College of Veterinary Medicine, Michigan State University, East Lansing 48824
}

\begin{abstract}
Excessive rates of demand lipolysis in the adipose tissue (AT) during periods of negative energy balance (NEB) are associated with increased susceptibility to disease and limited lactation performance. Lipolysis induces a remodeling process within AT that is characterized by an inflammatory response, cellular proliferation, and changes in the extracellular matrix (ECMT). The adipose tissue macrophage (ATM) is a key component of the inflammatory response. Infiltration of ATM-forming cellular aggregates was demonstrated in transition cows, suggesting that ATM trafficking and phenotype changes may be associated with disease. However, it is currently unknown if ATM infiltration occurs in dairy cows only during NEB states related to the transition period or also during NEB-induced lipolysis at other stages of lactation. The objective of this study was to evaluate changes in ATM trafficking and inflammatory phenotypes, and the expression of genetic markers of AT remodeling in healthy late-lactation cows during feed restriction-induced NEB. After a 14-d (d -14 to d -1) preliminary period, Holstein cows were randomly assigned to 1 of 2 feeding protocols, ad libitum (AL) or feed restriction (FR), for $4 \mathrm{~d}$ (d 1-4). Caloric intake was reduced in FR to achieve a targeted energy balance of $-15 \mathrm{Mcal} / \mathrm{d}$ of net energy for lactation. Omental and subcutaneous AT samples were collected laparoscopically to harvest stromal vascular fraction (SVF) cells on $\mathrm{d}-3$ and 4 . The FR induced a NEB of $-14.1 \pm 0.62$ $\mathrm{Mcal} / \mathrm{d}$ of net energy for lactation, whereas AL cows remained in positive energy balance $(3.2 \pm 0.66 \mathrm{Mcal} / \mathrm{d}$ of $\mathrm{NE}_{\mathrm{L}}$ ). The $\mathrm{FR}$ triggered a lipolytic response reflected in increased plasma nonesterified fatty acids (0.65 \pm $0.05 \mathrm{mEq} / \mathrm{L}$ on d 4), enhanced phosphorylation of hormone sensitive lipase, and reduced adipocyte diameter.
\end{abstract}

Received June 2, 2016.

Accepted August 19, 2016.

${ }^{1}$ Corresponding author: contre28@msu.edu
Flow cytometry and immunohistochemistry analysis revealed that on $\mathrm{d} 4, \mathrm{FR}$ cows had increased numbers of CD172a ${ }^{+}$, an ATM (M1 and M2) surface marker, cells in SVF that were localized in aggregates. However, FR did not alter the number of SVF cells expressing M1 markers (CD14 and CD11c) or M2 markers (CD11b and CD163). This finding contrasts with the predominately M1 phenotype observed previously in ATM from clinically diseased cows. No changes were observed in the expression of ECMT-related or cell proliferation markers. In summary, an acute 4-d lipolytic stimulus in late-lactation dairy cows led to ATM infiltration with minimal changes in inflammatory phenotype and no changes in ECMT. These results underscore that physiological changes related to parturition, the onset of lactation, extended periods of lipolysis, or a combination of these can induce intense AT remodeling with enhanced ATM inflammatory phenotype expression that may impair the metabolic function of AT in transition dairy cattle.

Key words: adipose tissue remodeling, fatty acid, lipolysis, macrophages

\section{INTRODUCTION}

Adipose tissue (AT) lipolysis is a dynamic physiological response that involves not only the release of free fatty acids from adipocyte triglyceride reserves but also a remodeling process (Kosteli et al., 2010). The remodeling is accompanied by an inflammatory response with immune cell migration, proliferation of cellular components of the stromal vascular fraction (SVF), and changes in the extracellular matrix (ECMT) within AT (Rutkowski et al., 2015). An increased rate of total lipolysis, defined as the sum of basal and demand lipolysis, is the triggering stimulus for AT remodeling (Kosteli et al., 2010). The rate of basal lipolysis is determined by adipocyte TG content (Arner and Langin, 2014). In contrast, demand lipolysis is regulated hormonally in response to energy requirements. In dairy 
cattle, pronounced and protracted demand lipolysis in periods of negative energy balance (NEB), such as during the transition period, are associated with increased susceptibility to disease (Ospina et al., 2013). Despite this important epidemiological association, features of AT remodeling during lipolysis remain poorly understood. Although immune cell migration and activation are important components of the AT remodeling process in nonruminant species (Ferrante, 2013), little is known about these processes in ruminants. We recently demonstrated macrophage infiltration into AT of transition dairy cows with displaced abomasum (DA) and intense demand lipolysis (Contreras et al., 2015). In those transition cows, adipose tissue macrophages (ATM) infiltrated omental (OM) and subcutaneous (SC) fat, forming cellular aggregates similar to those seen in obese rodents and humans (Contreras et al., 2015). In healthy postpartum heifers, Akter et al. (2012) reported increased numbers of ATM in OM and mesenteric AT depots $1 \mathrm{~d}$ after parturition. Collectively, these findings suggest ATM trafficking changes occur in the bovine periparturient period and may be associated with the pathogenesis of metabolic diseases; however, it is currently unknown if ATM infiltration occurs in dairy cattle only during NEB states related to the transition period or also during NEB-induced demand lipolysis at other stages of lactation.

The macrophage is the most abundant immune cell type in the SVF of AT in domestic cattle, sheep, goats, cats, and dogs (Ampem et al., 2016). In nonpregnant, nonlactating cows, this mononuclear cell type represents around $10 \%$ of the SVF population (Contreras et al., 2015). During intense lipolytic events, ATM are the key component of the active inflammatory response and play a major role in the remodeling process of AT in rodents and humans (Kosteli et al., 2010; Suganami and Ogawa, 2010). The ATM remove fatty acids that are released in excess during lipolysis and reduce lipotoxicity in interstitial tissue. The ATM are also involved in the recruitment of new adipocyte progenitors by secreting chemotactic proteins such as osteopontin (Lee et al., 2013). The specific inflammatory phenotype of ATM is dependent on the types and concentrations of local cytokines, chemokines, and fatty acids that shape gene and protein expression profile during inflammation. Classical phenotype ATM (M1) stimulate pro-inflammatory pathways and secrete cytokines including tumor necrosis factor $\alpha$ ( TNF $\mathbf{\alpha})$ and IL-6. Alternative phenotype ATM (M2) promote inflammation resolution by secreting cytokines such as IL-10 (Ferrante, 2013). Although it appears that M1 ATM are associated with intense periparturient lipolysis (Contreras et al., 2015), it is currently unknown if lipolysis during feed-restriction-induced NEB in mid and late lactation alters macrophage polarization and therefore could serve as a model for AT remodeling in transition cows.

Besides ATM infiltration, the AT remodeling process is also associated with changes in ECMT in monogastric animals. Increased deposition of collagen VI and thrombospondin during inflammatory responses in AT impairs adipocyte metabolic function by limiting lipid accumulation and insulin signaling (Varma et al., 2008; Pasarica et al., 2009). Less is known about the expression of ECMT proteins in dairy cows during lipolytic responses and their effect on AT metabolic function. In humans and rodents, AT remodeling with excessive infiltration of M1 ATM and increased deposition of ECMT impair adipocyte response to insulin, leading to enhanced total lipolysis that results in chronic elevation of circulating fatty acids. Characterizing AT remodeling in cows during NEB may identify mechanisms that lead to excessive rates of lipolysis that predispose transition cows to disease and poor lactation performance. Therefore, our objective was to evaluate changes in ATM trafficking and inflammatory phenotypes, and the expression of genetic markers of AT remodeling in healthy late-lactation cows during feed restrictioninduced NEB.

\section{MATERIALS AND METHODS}

\section{Cows}

All animal procedures were approved by the Michigan State University Animal Care and Use Committee. Late-lactation (223 DIM $\pm 103 \mathrm{SD}$ ) bovine leukemia virus seronegative Holstein cows from the Michigan State University Dairy Field Laboratory (East Lansing, MI) were randomly assigned to 1 of 2 feeding protocols: ad libitum (AL) or feed-restricted (FR) in 2 separate blocks. In block 1, which was performed in August 2014,8 cows in their second $(n=4)$, third $(n=2)$, and fourth $(\mathrm{n}=2)$ lactations were selected. Cows were fed a common diet during a 14-d preliminary period (d -14 to -1 ) and then randomly assigned based on lactation number to $\mathrm{AL}(\mathrm{n}=4)$ or $\mathrm{FR}(\mathrm{n}=4)$ treatments. Average milk yields during the preliminary period were $35.6 \pm 8.8 \mathrm{~kg}$ and $39.4 \pm 6.2 \mathrm{~kg}$ for the AL and FR groups, respectively. The BCS scores before FR were $\mathrm{AL}=3.1 \pm 0.1$ and $\mathrm{FR}=3.3 \pm 0.2$. One cow from $\mathrm{AL}$ was removed from the study due to a health event before the beginning of the treatments. Caloric intake was reduced in FR cows for $4 \mathrm{~d}$ (d 1 to 4 ) to achieve a targeted NEB of $-15 \mathrm{Mcal} / \mathrm{d}$ of $\mathrm{NE}_{\mathrm{L}}$ similar to the transition period ( 3 wk before to 3 wk after calving; 
Koltes and Spurlock, 2011). In block 2, which was performed in November 2014, 6 cows in their first ( $\mathrm{n}=$ 2 ) or second lactation $(\mathrm{n}=4)$ were randomly assigned based on lactation number to FR and AL treatments as described for block 1 . Two cows from block 1 were used in block 2 but were assigned to the opposite treatment. Preliminary period milk yields for cows in block 2 were $32.6 \pm 5.2(\mathrm{AL})$ and $29.1 \pm 1.4(\mathrm{FR})$. The BCS at the end of the preliminary period were $3.6 \pm 0.2$ and 3.3 \pm 0.1 for cows in the AL and FR groups, respectively.

\section{Feed Restriction Protocol}

The ingredient and nutrient composition of the diets fed as a TMR in blocks 1 and 2 are described in Table 1. Minerals and vitamins were formulated according to NRC (2001) recommendations. Samples of all diet ingredients $(0.5 \mathrm{~kg})$ were collected daily and composited during the preliminary period and FR protocols from d 1 to 4. Samples were analyzed for NDF, CP, starch, and fatty acid concentrations as described by Boerman et al. (2015). Baseline BW, DMI, and the yield of milk and milk components were measured for $5 \mathrm{~d}$ before feed restriction. Feed was restricted for $4 \mathrm{~d}$ with the quantity of TMR provided to each cow adjusted on d 3 of the feed restriction period to account for changes in milk production. Cows were fed 2 times daily throughout the preliminary and FR periods. Net energy balance was estimated as the difference between $\mathrm{NE}_{\mathrm{L}}$ consumed

Table 1. Ingredient and nutrient composition of the treatment diet

\begin{tabular}{lcc}
\hline Item & Block 1 & Block 2 \\
\hline Ingredient (\% of DM) & 21.9 & 32.1 \\
Corn silage & 13.5 & 16.3 \\
Alfalfa silage & 2.5 & - \\
Wheat straw & 19.6 & 25.1 \\
Dry ground corn & 9.1 & - \\
High moisture corn & 16.0 & 15.9 \\
Soybean meal & 6.9 & - \\
Soy hulls & 7.1 & 7.2 \\
Cottonseed with lint & 2.0 & 2.0 \\
Vitamin-mineral mix & 0.64 & 0.66 \\
Limestone & 0.73 & 0.75 \\
Sodium bicarbonate & & \\
Nutrient composition (\% of DM) & 56.4 & 51.6 \\
DM & 30.2 & 28.0 \\
NDF & 17.4 & 17.5 \\
CP & 22.2 & 29.5 \\
Starch & 3.4 & 3.5 \\
Fatty acid & & \\
\hline
\end{tabular}

${ }^{1}$ Vitamin and mineral mix contained $34.1 \%$ dry ground shell corn, $25.6 \%$ white salt, $21.8 \%$ calcium carbonate, $9.1 \%$ Biofos (The Mosaic Co., Plymouth, MN), $3.9 \%$ magnesium oxide, $2 \%$ soybean oil, and $<1 \%$ of trace minerals including $(\mathrm{g} / 100 \mathrm{~g}) 2.0$ copper, 12.0 sulfur, 10.5 zinc, 0.3 manganese, 0.25 cobalt, 0.19 iodine, a selenium blend containing $0.006 \%$ sodium selenite, and vitamin ADE mixture containing $(\mathrm{g} / \mathrm{kg}) 10.8$ retinyl acetate, 0.18 cholecalciferol, and $0.047 \mathrm{DL}-\alpha-$ tocopherol. and used for milk production and maintenance (NRC, 2001).

\section{Sample Collection and Analysis}

Blood and milk were collected on $\mathrm{d}-7,-3,-2$, and -1 and then daily from d 1 to 4 . Total plasma nonesterified fatty acid (NEFA) concentrations were quantified using the NEFA-HR-2 kit (Wako, Richmond, VA) as described previously (Contreras et al., 2010). Plasma insulin was determined by ELISA following manufacturer guidelines (Bovine Insulin ELISA; Mercodia AB, Uppsala, Sweden) and using a Synergy H1 Microplate Reader (Biotek, Winooski, VT). Intra- and interassay CV were 4.1 and $4.3 \%$, respectively. Circulating glucose values were determined using an Olympus AU640e chemistry analyzer (Olympus America, Center Valley, PA) at the Diagnostic Center for Population and Animal Health (Lansing, MI). Milk samples were analyzed by the Northstar Cooperative Dairy Herd Improvement (Northstar Laboratories, East Lansing, MI) as described previously (Boerman et al., 2015).

Omental and SC AT samples were collected on d -3 and 4 laparoscopically. In brief, cows received local flank anesthesia using an inverted L block with $20 \mathrm{~mL}$ of $2 \%$ lidocaine hydrochloride (Aspen Veterinary Resources, Greeley, CO). Two 1-cm incisions were made through the skin in the right paralumbar fossa. The external abdominal oblique, internal abdominal oblique, and transverse abdominus muscles were incised. Next, the peritoneum was incised and the laparoscopic equipment was introduced in the incisions, pneumoperitoneum $(10 \mathrm{mmHg})$ was established, and suitable location(s) for OM adipose sampling identified. Using cup biopsy forceps, $3 \mathrm{~g}$ of OM tissue were collected. A 3-g SC sample was collected from the area of the incisions before its closure using synthetic absorbable material in a buried suture pattern. Total surgical time was less than 20 min per animal. For cows in block 2 , instead of laparoscopic collection of AT on d 4, samples (matching sites used for laparoscopic OM biopsy) were collected postmortem at the Michigan State University Meat Laboratory.

\section{Adipose Tissue Processing}

Immediately after harvesting, AT were divided and stored for further processing. Samples for protein analysis were snap frozen and stored at $-80^{\circ} \mathrm{C}$. For gene expression analysis, samples were stored in RNA Later (Life Technologies, Carlsbad, CA). Samples for histology were immersed in $4 \%$ paraformaldehyde (Electron Microscopy Sciences, Hartfield, PA) or $30 \%$ sucrose in distilled water (vol:vol). For tissue 
fractionation, samples were collected in Krebs Ringer bicarbonate buffered solution containing $50 \mu \mathrm{g} / \mathrm{mL}$ of gentamicin (MP Biochemicals, Solon, OH) and HEPES $10 \mathrm{mM}(\mathrm{pH}=7.4)$ and transported immediately to the laboratory where adipocytes and SVF were obtained by collagenase digestion of AT, as previously described (Contreras et al., 2015).

\section{Flow Cytometry Analysis}

Macrophage distribution and phenotype in SVF of AT were determined using flow cytometry as previously described (Contreras et al., 2015). Mouse anti-bovine antibodies were obtained from the Washington State University Monoclonal Antibody Center (Pullman, WA): B cells (S-BAQ44A; 1:100), CD3 (MM1A; 1:100), CD11b (BAQ150A; 1:100), CD11c (BAQ153A; 1:100), CD14 (MM61A; 1:50), CD172a (DH59B; 1:100); and AbD Serotec (Raleigh, NC): CD163 (MCA2311GA; 1:100). Secondary goat anti-mouse FITC was from Jackson Immnunoresearch (West Grove, PA). Flow cytometry analysis was performed using the FACSdiva software on an LSRII Flow Cytometer (BD Biosciences, San Jose, CA).

\section{Quantitative PCR Analysis}

Adipose tissue RNA was extracted using Trizol reagent (Life Technologies, Grand Island, NY) according to the manufacturer's directions and then purified using the RNA Easy Mini Kit (Qiagen, Valencia, CA) as described previously (Contreras et al., 2014). Purity, concentration, and integrity of mRNA were evaluated using a NanoDrop 1000 spectrophotometer (Thermo Scientific, Wilmington, DE) and an Agilent Bioanalyzer 2100 (Agilent Technologies, Santa Clara, CA) system. All samples had a 260:280 nm ratio between 1.9 and 2.1 and an RNA integrity number $>6$. Conversion to cDNA was performed using the Applied Biosystems High Capacity cDNA Archive Kit (Applied Biosystems, Foster City, CA). All quantitative PCR assays were conducted with TaqMan gene expression primers and reagents from Applied Biosystems. Taq primers were either commercially available or designed from bovine sequences with the Applied Biosystems Pipeline software and synthesized by Applied Biosystems Inc. (Supplemental Table S1; http://dx.doi.org/10.3168/jds.2016-11552). Samples were assayed in triplicate on the Wafergen Smartchip System (WaferGen Biosystems, Fremont, $\mathrm{CA}$ ) using cDNA at a primer-efficient concentration of $714 \mathrm{pg} / \mu \mathrm{L}$. A non-reverse-transcriptase control sample validated absence of genomic DNA. Data are presented as fold changes relative to the AL SC samples. These were calculated from least squares mean differ- ences according to the formula $2^{-\Delta \Delta \mathrm{Ct}}$, where $\Delta \mathrm{Ct}=$ $\mathrm{Ct}_{\text {Target gene }}-\mathrm{Ct}_{\text {Control gene, }}$, and $\Delta \Delta \mathrm{Ct}=\Delta \mathrm{Ct}_{\text {Target Sample }}$

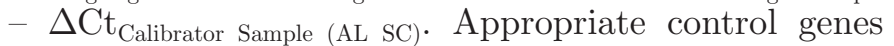
were selected as previously described (Steibel et al., 2009) using Data Assist software (Applied Biosystems) and included EIF3K, B2M, and RPS9. For reporting, expression data were normalized to the mean of these housekeeping genes. All statistical analysis was performed on the $\Delta \mathrm{Ct}$ values as described by Steibel et al. (2009).

\section{Immunohistochemistry}

Localization of ATM was determined using immunolabelling of paraffin sections using the Autostainer Link 48 (Dako North America Inc., Carpinteria, CA) automated stainer and a mouse monoclonal anti-CD172a (DH59B; 1:100) antibody (Contreras et al., 2015). The ATM aggregates, defined as clusters of CD172a ${ }^{+}$cells, were quantified within 100 contiguous adipocytes from 5 randomly selected fields per section. Imaging was performed using an Olympus BX-40 microscope (Olympus, Center Valley, PA). Adipocyte cell diameters were determined as described earlier (Verdes et al., 2013) in hematoxylin- and eosin-stained sections of paraformaldehyde fixed paraffin-embedded tissue. Diameters of 100 adjacent cells from each of 5 randomly selected fields were measured using ImageJ software (National Institutes of Health, Bethesda, MD).

\section{Western Blotting}

Protein quantification was performed by Western blot analysis as previously described (Contreras et al., 2014). Protein was extracted in RIPA buffer (Teknova, Hollister, CA) containing protease (Roche, San Francisco, CA) and phosphatase (Thermo Scientific, Waltham, MA) inhibitors. Equal sample amounts of protein (30 $\mu \mathrm{g})$ were electrophoresed on a 4 to $20 \%$ SDS-PAGE gel and transferred to a polyvinylidene difluoride membrane. The membrane was blocked in Tris-buffered saline (TBS) with $0.01 \%$ Tween-20 and 5\% BSA and washed 3 times with TBS. Membranes were incubated overnight with primary antibodies in TBS with $0.01 \%$ Tween-20 and 5\% BSA. Antibodies were from Cell Signaling Technology (Danvers, MA) and included rabbit anti-mouse hormone sensitive lipase (HSL, 1:1000, \#4107), rabbit anti-mouse phosphorylated HSL serine 660 (1:1,000, \#4126), and rabbit anti-human $\alpha / \beta$ tubulin as loading control (1:1,000, \#2148). Following 3 washes with TBS, membranes were incubated with the correspondent anti-host IgG secondary antibody labeled with horseradish peroxidase (1:10,000 dilution in $5 \%$ BSA, Jackson Immunoresearch) for 10 min at room 
temperature, washed 3 times with TBS, exposed to horseradish peroxidase substrate (Millipore, Billerica, MA). Protein bands were visualized by chemiluminescence using the ChemiDoc XRS (Bio-Rad, Hercules, CA). Density of the bands was quantified by the Quantity One software (Bio-Rad).

\section{Statistical Analyses}

Statistical analysis was conducted using Proc MIXED (SAS version 9.4, SAS Institute Inc., Cary, NC). The production, plasma glucose, and serum insulin data were analyzed with linear models that included the fixed effects of treatment, block, preliminary milk yield (pMilk), and their interactions. pMilk was defined as the milk yield of each cow on $d-1$ relative to the feed restriction period. The qPCR, Western blot, flow cytometry, immunohistochemistry, and adipocyte diameter data were analyzed with linear models that included the fixed effects of treatment, block, tissue site, and their interactions. Plasma NEFA concentrations were analyzed with a repeated measures model that included the effects of treatment, block, day (repeated), pMilk, and their interactions. An autoregressive covariance structure was selected for the repeated measures model based on the model Akaike information criterion value. Interaction terms were removed from the models when $P>0.20$. Least squares means differences were determined by $t$-tests using the PDIFF option. Data, with the exception of the gene expression fold changes, are reported as least squares means \pm standard error of the mean. The $95 \%$ confidence intervals of the gene expression fold changes (Supplemental Table S2; http:// dx.doi.org/10.3168/jds.2016-11552) were transformed from the $95 \%$ confidence intervals of the $\Delta \Delta \mathrm{Ct}$ values estimated as least squares mean differences of $\Delta \mathrm{Ct}$ values. Main effects, least squares mean differences, and interaction terms were considered significant when $P \leq$ 0.05 and tendencies when $P<0.10$.

\section{RESULTS}

\section{FR Induces NEB and Lipolysis}

Whereas AL cows remained in positive energy balance for the duration of the experiment $(3.2 \pm 0.66$ $\mathrm{Mcal} / \mathrm{d}$ of $\mathrm{NE}_{\mathrm{L}}$ ), limiting caloric intake in $\mathrm{FR}$ cows induced a NEB of $-14.1 \pm 0.62 \mathrm{Mcal} / \mathrm{d}$ of $\mathrm{NE}_{\mathrm{L}}$ (Table 2 ). To compensate for reduced energy availability, cows in the FR group had a lipolytic response characterized by a progressive, marked increase in plasma NEFA concentrations over the course of the feed restriction period (Figure 1A). By d 4, FR increased NEFA concentrations to $0.65 \mathrm{mEq} / \mathrm{L}$ compared with $0.16 \mathrm{mEq} / \mathrm{L}$ in $\mathrm{AL}$ group $(P<0.01)$. Lipolytic activity was demonstrated in $\mathrm{OM}$ and $\mathrm{SC}$ adipose depots by increased phosphorylation of HSL at $\operatorname{Ser}^{660}$ (Figure 1B). As expected, OM adipocytes were larger than SC before and after treatment (Figure 1C). Reflecting enhanced lipid mobilization, FR reduced adipocyte diameter in $\mathrm{OM}$ and SC adipose compared with AL (Figure 1C). The FR tended to have a lower concentration of plasma insulin by d 4 compared with $\mathrm{AL}(P=0.07)$; however, circulating glucose concentrations remained unaltered (Figure 1D). In response to $4 \mathrm{~d}$ of caloric restriction, the expression of lipogenic genes $F A S N, S C D 1$, and ELOVL6, and the lipolytic gene ABHD5 $(P<0.05)$ were reduced in $\mathrm{OM}$ and $\mathrm{SC}$ adipose. The transcription of the gene encoding ATGL (PNPLA2; $P=0.08$ ) tended to be downregulated in both tissues from FR. Although FR did not alter the expression of fatty acid transporter $F A B P 4$, the treatment $\times$ site interaction for this gene was significant $(P=0.04)$. The FR had no effect on the transcription of $L I P E$ that encodes HSL and the adipogenic regulator gene PPARG (Table 3).

\section{NEB Reduces Milk Production and Alters Composition}

As expected, milk yield, ECM, and FCM were reduced in the FR group after $4 \mathrm{~d}$ of limiting feed intake (Table 2). In contrast, FR increased fat yield $(P=$ $0.03)$ and tended to elevate milk fat concentration $(P$ $=0.09$ ). Higher producing cows exhibited a stronger increase in fat yield and milk fat concentration $(P=$ $0.04,0.06)$, but a larger decrease in ECM and FCM in response to FR $(P=0.07,0.09$; Table 2$)$. Reducing caloric intake negatively affected milk protein yield $(P$ $<0.01)$. However, no differences were observed in milk protein concentration. Similarly, FR reduced lactose yield and concentration $(P<0.01$ and $P=0.02$, respectively). No differences were found in milk, fat, and lactose production or concentration responses to FR between blocks 1 and 2 .

\section{NEB Alters ATM Trafficking, But Does Not Affect Phenotype}

The qPCR analysis of $\mathrm{OM}$ and $\mathrm{SC}$ adipose revealed that the expression of M1-related gene TNFA tended to be upregulated by FR $(P=0.06$; Table 3$)$. In contrast, expression of M1 related pro-inflammatory gene $C C L 2$ was not affected by caloric restriction. Though FR did not alter the expression of ITGAX, a gene encoding the M1 related surface protein $\mathrm{CD} 11 \mathrm{c}$, the treatment $\times$ site interaction for this gene was significant $(P=$ $0.04)$. Transcriptions of M2-related anti-inflammatory genes ARG1 and IL10 were not affected by treatment 
( $P=0.11$ and $P=0.22$, respectively). No treatment or site effects were observed in the expression of the M2-related gene CCL22. The expression of SIRPA, a marker of mononuclear immune cells, was decreased by $\mathrm{FR}$ and its expression was lower in $\mathrm{OM}$ adipocytes of both AL and FR, compared with SC $(P=0.03)$. Based on flow cytometry analysis, FR increased the number of cells expressing the mononuclear cell marker CD172a (Table 4). The expression of CD14 and CD11c, both M1 markers, were unaltered. The FR did not have an effect on the number of $\mathrm{CD} 11 \mathrm{c}^{+}$cells in $\mathrm{OM}$ or SC; however, the treatment by site interaction for this marker was significant $(P=0.05$; Table 4$)$. More B cells were detected in OM fat than in SC fat; however, no effect of treatment was found (Table 4). Immunohistochemical analysis of OM and SC AT sections using anti-CD172a, a mononuclear immune cell specific marker, was used to determine ATM localization. The FR increased the number of ATM aggregates compared with AL ( $P$ $=0.02)$; however, the number of aggregates was not affected by site $(P=0.07$; Figure 2$)$. Notably, ATM aggregates did not contain lipid remnants or exhibit multinucleated cells.

\section{ECMT Gene Expression Varies by AT Site But Is Not Affected by NEB}

Expression of ECMT protein genes COL1A1 and COL6A2 was higher in $\mathrm{SC}$ than $\mathrm{OM}$ adipose $(P=$ 0.01 and $P<0.01$, respectively); however, they were not affected by treatment (Table 3 ). In contrast, the expression of THBS1 was similar in both sites and was not influenced by treatment. Finally, no effect of treatment was observed on the expression of cell cycle genes CCNA2, CCNB2, and MKI6r\%, indicating no mitogenic effects. The expression of SPP1 and CD44, the osteopontin and osteopontin receptor encoding genes, was not affected by treatment or site.

\section{DISCUSSION}

Although excessive lipolysis is a predisposing factor to disease and poor lactation performance in transition and early lactation cows, the number of confounding variables associated with parturition and the onset of lactation limit the interpretation of a single physiological process, such as lipolysis, on AT responses to NEB. Several research groups recognized this problem and designed experiments using mid- and late-lactation cows where early lactation NEB or lipolytic conditions are mimicked (Bjerre-Harpøth et al., 2012; Akbar et al., 2013; Pires et al., 2016). The main advantage of feed restriction in lipolysis models is that energy balance can be adjusted to mimic the transition period (Faylon et al., 2014). In our present study, we were able to emulate several metabolic features of transition dairy cows' metabolic function. First, plasma NEFA concentrations were increased in FR cows to simulate circulating NEFA concentrations observed in transition dairy cows. This lipolytic response was similar to that reported in other studies using 4-d feed restriction protocols (Faylon et al., 2014; Pires et al., 2016). Second, lipase activity at

Table 2. The effect of feed-restriction-induced negative energy balance and lipolysis on DMI, yield of milk and milk components, and energy balance of dairy cows ${ }^{1}$

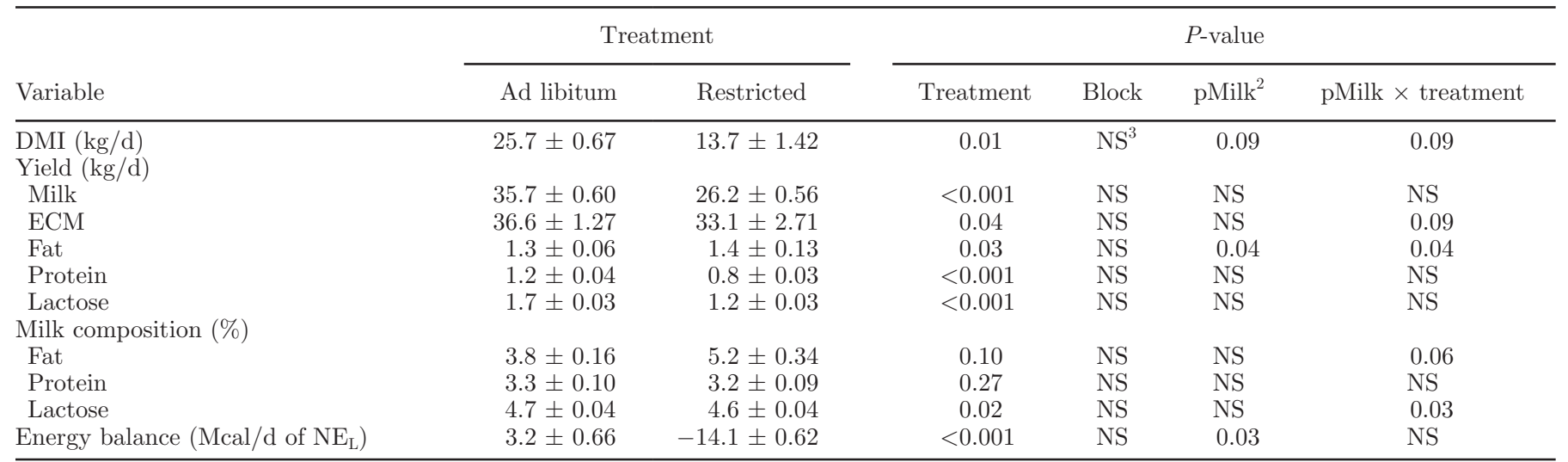

${ }^{1}$ Late lactation dairy cows $(\mathrm{n}=13)$ were randomly assigned to 1 of 2 feeding protocols: ad libitum $(\mathrm{AL}, \mathrm{n}=6)$ or feed-restricted $(\mathrm{FR}, \mathrm{n}=7)$. Caloric intake was reduced in FR cows for $4 \mathrm{~d}$ to achieve a targeted negative energy balance of $-15 \mathrm{Mcal} / \mathrm{d}$ of $\mathrm{NE}_{\mathrm{L}}$ with the quantity of TMR provided to each cow adjusted on d 3 of the feed restriction period to account for changes in milk production. Data are least squares means \pm SEM.

${ }^{2}$ pMilk $=$ preliminary milk yield.

${ }^{3} \mathrm{NS}=P>0.10$. 
A

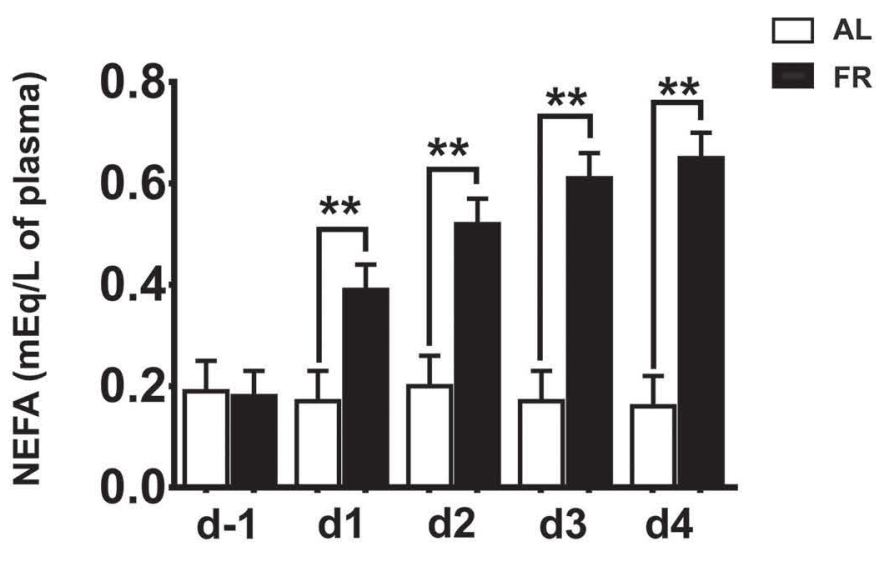

B

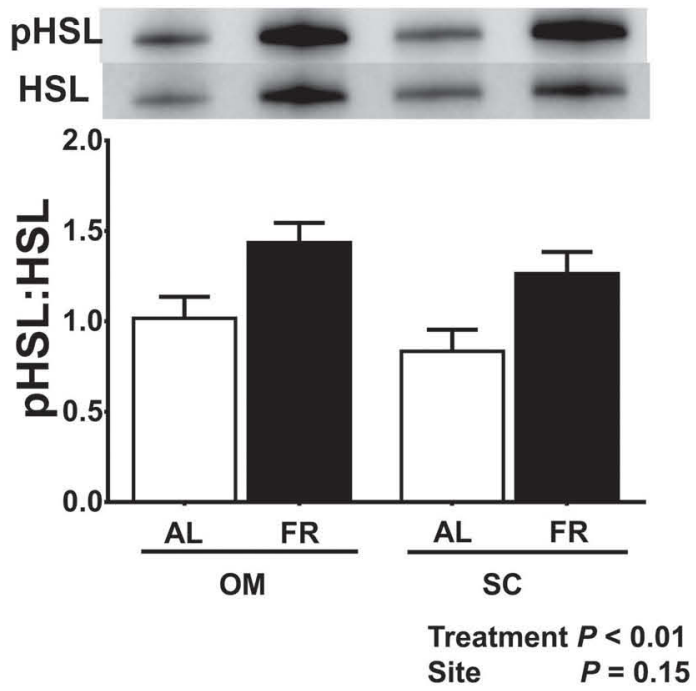

D
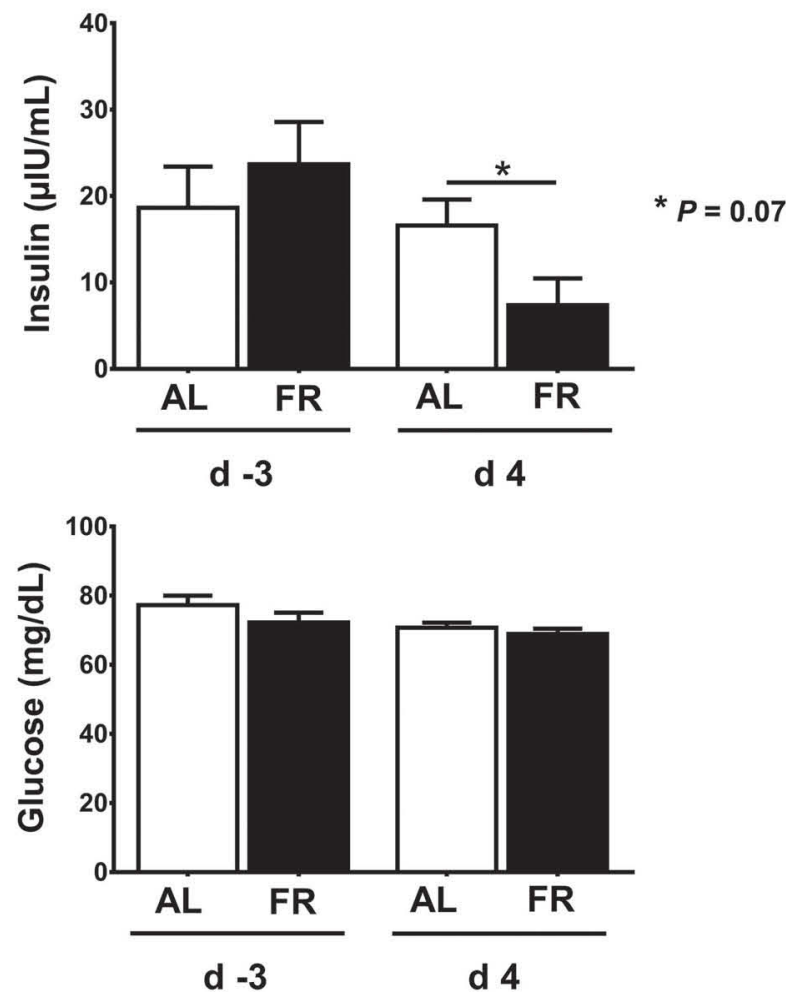

Figure 1. Feed-restriction-induced negative energy balance increases lipolysis in lactating dairy cows. Lipolysis markers including plasma nonesterified fatty acids (NEFA; A), phosphorylation ratio (at Serine ${ }^{660}$ ) of hormone sensitive lipase (HSL) in omental (OM) and subcutaneous (SC) adipose depots (B), adipocyte diameters in OM and SC fat depots (C), and plasma insulin and glucose (D) were evaluated in late-lactation dairy cows. pHSL $=$ rabbit anti-mouse phosphorylated HSL serine 660. Animals were randomly assigned to ad libitum $(\mathrm{AL}, \mathrm{n}=6)$ or feedrestricted $(\mathrm{FR}, \mathrm{n}=7$ ) feeding protocols for $4 \mathrm{~d}$ to achieve a targeted negative energy balance of $-15 \mathrm{Mcal} / \mathrm{d}$ of $\mathrm{NE}$. Data are $\mathrm{LSM} \pm \mathrm{SEM}$. Significant differences are indicated by $* *(P<0.01)$ and tendencies are indicated by $*(0.05<P<0.10)$.

the lipid droplet level increased in FR cows, reflected by enhanced HSL phosphorylation at Ser ${ }^{660}$ (Choi et al., 2010), and mimicked lipase activity during the first
2 wk after parturition (Koltes and Spurlock, 2011). Third, lipogenic gene networks were downregulated in FR cows, including fatty acid synthase $(F A S N)$ and 
Table 3. The effect of feed-restriction-induced negative energy balance and lipolysis on the expression of genes related to lipid mobilization, extracellular matrix, and adipose tissue macrophage (ATM) phenotype and inflammation of dairy cows ${ }^{1}$

\begin{tabular}{|c|c|c|c|c|c|c|c|c|}
\hline \multirow{2}{*}{ Network } & \multirow{2}{*}{ Gene } & \multicolumn{4}{|c|}{ Fold change relative to ad libitum subcutaneous ${ }^{2,3}$} & & & \\
\hline & & \multicolumn{2}{|c|}{ Ad libitum } & \multicolumn{2}{|c|}{ Restricted } & \multicolumn{3}{|c|}{$P$-value } \\
\hline \multirow[t]{6}{*}{ Lipid mobilization } & ABHD5 & $1^{\mathrm{ab}}$ & $1.44^{\mathrm{a}}$ & $0.82^{\mathrm{bc}}$ & $0.55^{\mathrm{c}}$ & $<0.01$ & $\mathrm{NS}^{4}$ & 0.03 \\
\hline & ELOVL6 & 1 & 4.06 & 0.20 & 0.20 & $<0.01$ & NS & 0.09 \\
\hline & PNPLA2 & 1 & 2.08 & 0.91 & 0.70 & 0.09 & NS & NS \\
\hline & $F A B P 4$ & 1 & 1.78 & 2.07 & 1.05 & NS & NS & 0.04 \\
\hline & $L I P E$ & 1 & 2.02 & 2.06 & 1.13 & NS & NS & NS \\
\hline & $P P A R G$ & 1 & 1.65 & 1.05 & 0.81 & NS & NS & NS \\
\hline \multirow[t]{4}{*}{ Extracellular matrix } & COL1A1 & 1 & 0.19 & 0.76 & 0.33 & NS & $<0.01$ & NS \\
\hline & COL6A2 & 1 & 0.30 & 0.87 & 0.46 & NS & $<0.01$ & NS \\
\hline & THBS1 & 1 & 0.44 & 0.78 & 1.02 & NS & NS & NS \\
\hline & CCNA2 & 1 & 1.15 & 0.90 & 1.44 & NS & NS & NS \\
\hline \multirow{7}{*}{$\begin{array}{l}\text { ATM phenotype } \\
\text { inflammation }\end{array}$} & CCL2 & 1 & 0.52 & 0.93 & 0.83 & NS & NS & NS \\
\hline & CCL22 & 1 & 0.34 & 0.46 & 0.81 & NS & NS & NS \\
\hline & IL 6 & 1 & 0.50 & 0.71 & 0.88 & NS & NS & NS \\
\hline & IL10 & 1 & 0.76 & 1.48 & 1.10 & NS & NS & NS \\
\hline & ITGAX & $1^{\mathrm{a}}$ & $0.46^{\mathrm{ab}}$ & $\begin{array}{l}1.4 \mathrm{o} \\
0.23^{\mathrm{b}}\end{array}$ & $0.70^{\mathrm{ab}}$ & NS & NS & 0.04 \\
\hline & TNFA & 1 & 0.75 & 1.54 & 1.13 & 0.06 & NS & NS \\
\hline & SIRPA & 1 & 0.58 & 0.57 & 0.41 & 0.03 & 0.03 & NS \\
\hline
\end{tabular}

${ }^{\mathrm{a}-\mathrm{c}}$ Fold changes without a common superscript within a row represent differences determined by $t$-tests of the $\Delta$ Ct values.

${ }^{1}$ Late-lactation dairy cows $(\mathrm{n}=13)$ were randomly assigned to 1 of 2 feeding protocols: ad libitum $(\mathrm{AL}, \mathrm{n}=6)$ or feed-restricted $(\mathrm{FR}, \mathrm{n}=7)$. Caloric intake was reduced in FR cows for $4 \mathrm{~d}$ to achieve a targeted negative energy balance of $-15 \mathrm{Mcal} / \mathrm{d}$ of $\mathrm{NE}_{\mathrm{L}}$ with the quantity of TMR provided to each cow adjusted on $\mathrm{d} 3$ of the feed restriction period to account for changes in milk production. Data are presented as fold changes relative to the ad libitum subcutaneous sample.

${ }^{2}$ Fold change $=2^{(-\Delta \Delta \mathrm{Ct})} ; \Delta \Delta \mathrm{Ct}=\Delta \mathrm{Ct}_{\text {calibrator sample }}-\Delta \mathrm{Ct}_{\text {target sample. }}$.

${ }^{3}$ Gene expression fold changes were calculated from LSM differences of the $\Delta \mathrm{Ct}$ values $(\Delta \Delta \mathrm{Ct})$ normalized to the mean of EIF3K, B2M, and RPS9 housekeeping genes. The ad libitum subcutaneous sample was the calibrator for the calculation of $\Delta \Delta$ Ct. $95 \%$ confidence intervals of the $\Delta \Delta \mathrm{Ct}$ values were transformed to fold changes and are presented in Supplemental Table S2 (http://dx.doi.org/10.3168/jds.2016-11552).

${ }^{4} \mathrm{NS}=P>0.10$.

Table 4. The effect of feed-restriction-induced negative energy balance and lipolysis on immune cell trafficking in omental and subcutaneous adipose tissues of dairy cows ${ }^{1}$

\begin{tabular}{|c|c|c|c|c|c|c|c|}
\hline Surface marker ${ }^{2}$ & \multicolumn{2}{|c|}{ Ad libitum } & \multicolumn{2}{|c|}{ Restricted } & \multicolumn{3}{|c|}{$P$-value } \\
\hline CD14 & $4.08 \pm 0.86$ & $4.42 \pm 0.86$ & $4.82 \pm 0.86$ & $5.10 \pm 0.86$ & NS & NS & NS \\
\hline CD11b & $4.37 \pm 1.07^{\mathrm{ab}}$ & $3.45 \pm 1.07^{\mathrm{a}}$ & $3.42 \pm 1.07^{\mathrm{a}}$ & $6.93 \pm 1.07^{\mathrm{b}}$ & NS & NS & 0.05 \\
\hline CD11c & $1.92 \pm 0.92$ & $3.77 \pm 0.73$ & $4.17 \pm 0.73$ & $4.12 \pm 0.73$ & NS & NS & NS \\
\hline CD163 & $2.44 \pm 0.46$ & $2.75 \pm 0.54$ & $2.77 \pm 0.46$ & $2.79 \pm 0.60$ & NS & NS & NS \\
\hline
\end{tabular}

$\overline{\mathrm{a}, \mathrm{b}}$ Least squares means without a common superscript within a row represent differences determined by $t$-tests.

${ }^{1}$ Late-lactation dairy cows $(\mathrm{n}=13)$ were randomly assigned to 1 of 2 feeding protocols: ad libitum $(\mathrm{n}=6)$ or feed-restricted $(\mathrm{n}=7)$. Caloric intake was reduced in feed-restricted cows for $4 \mathrm{~d}$ to achieve a targeted negative energy balance of $-15 \mathrm{Mcal} / \mathrm{d}$ of $\mathrm{NE}_{\mathrm{L}}$ with the quantity of TMR provided to each cow adjusted on $\mathrm{d} 3$ of the feed restriction period to account for changes in milk production.

${ }^{2}$ Values are least squares means of percentages of stromal vascular fraction cells expressing phenotype surface markers \pm SEM as measured by flow cytometry using specific bovine monoclonal antibodies.

${ }^{3} \mathrm{NS}=P>0.10$. 
A
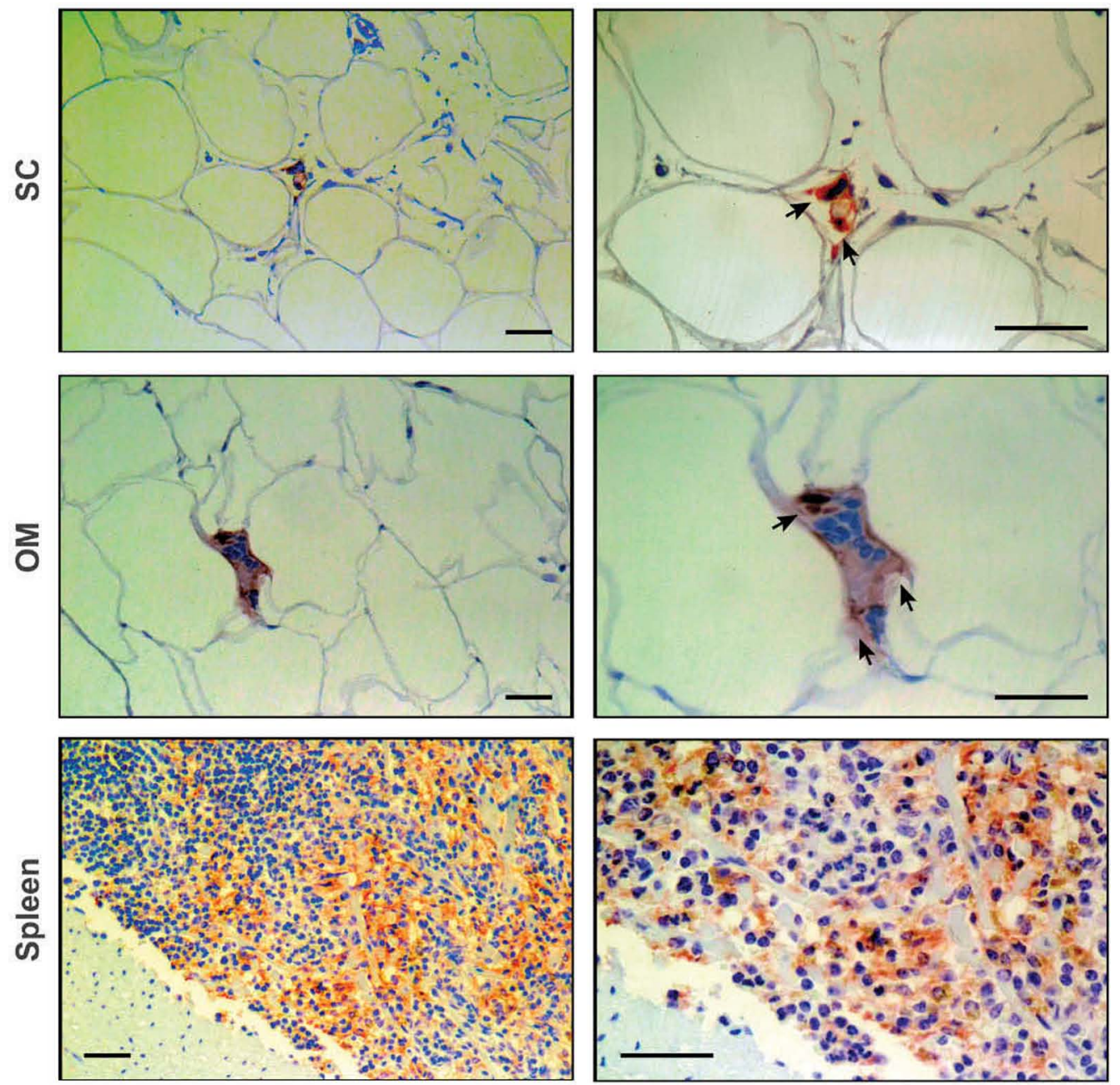

B

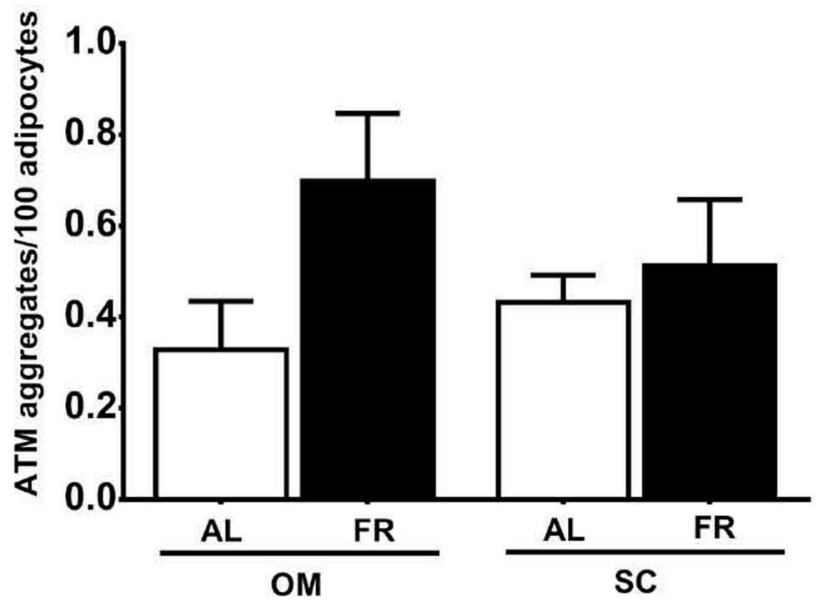

Treatment $P=0.02$

Site $\quad P=0.7$

Figure 2. Adipose tissue macrophage (ATM) aggregation is increased in cows during feed-restriction-induced negative energy balance. The ATM localization was evaluated by immunostaining of omental (OM) and subcutaneous ( $\mathrm{SC}$ ) adipose tissue sections from late-lactation dairy cows after $4 \mathrm{~d}$ of an ad libitum $(\mathrm{AL}, \mathrm{n}=6)$ or feed-restricted $(\mathrm{FR}, \mathrm{n}=7)$ feeding protocol. (A) High and low magnification images of SC and $\mathrm{OM}$ adipose tissues and representative images of spleen, representing a positive tissue control, from a FR cow. Black arrows indicate immunoreactive CD172a macrophages. Scale bars $=50 \mu \mathrm{m}$. (B) Number of ATM aggregates per 100 adipocytes in OM and SC adipose tissues of AL and FR cows. Data are LSM \pm SEM. Color version available online. 
elongase (ELOVL6). This occurs in transition dairy cows in response to hypoinsulinemia and lipolysis and is exacerbated in cows of high genetic merit (Khan et al., 2013). Finally, our results also emulate periparturient metabolic status because of hypoinsulinemia (De Koster and Opsomer, 2013). Interestingly, our feed restriction model did not induce hypoglycemia, a common observation in transition dairy cows. Previous feed restriction studies have reported similar results (Velez and Donkin, 2005; Oikawa and Oetzel, 2006), whereas others indicated a reduction in plasma glucose (Gross et al., 2011b; Ferraretto et al., 2014). Divergent results may be related to the DIM at the time of feed restriction because studies with cows around 100 DIM had lower circulating glucose compared with cows $>150$ DIM (Gross et al., 2011b). Additionally, a reduction in glycemia may be mitigated by gluconeogenesis from propionate, lactate, or glycerol. The latter is an important lipolysis product in animals during NEB (Herdt, 2000; Reynolds et al., 2003).

Previous studies found that NEB and lipolysis alter milk composition and production (Palmquist et al., 1993). Higher availability of circulating NEFA is rapidly reflected in milk fat as the mammary gland actively utilizes plasma NEFA for milk fat synthesis (Pullen et al., 1989). Higher milk fat is characteristic during the first week after calving and is greatly affected by the intensity and duration of lipolysis as a NEB response (van Knegsel et al., 2007; Mann et al., 2015). Similar to other feed restriction studies in early (Nielsen et al., 2003) and mid lactation (Gross et al., 2011a) cows, NEB-induced lipolysis in FR cows increased milk fat yield and concentration in our study, reflecting higher availability of circulating fatty acids to the mammary gland. Interestingly, the increase in fat concentration and yield due to FR was positively associated with milk production before feed restriction. Although plasma NEFA concentrations during FR were not affected by milk production before caloric restriction, it is unclear if lipolytic responses to NEB in late lactation are affected by previous levels of milk production, as has been reported in early lactation cows (Khan et al., 2013). Although conjecture, a higher lipolytic response to NEB in high producing cows in late lactation may be reflected in higher milk fat yield and concentration, but similar plasma NEFA compared with lower producing cows.

Transition cow AT inflammation is characterized by higher gene expression of pro-inflammatory cytokines including TNFa and IL-6 (Sadri et al., 2010; Schmitt et al., 2011). In our group of late-lactation cows, only TNFA gene expression was upregulated in response to lipolysis and no changes were observed in the transcript of additional cytokines considered early markers of in- flammation in dairy cattle such as IL-6 and macrophage chemoattractant protein 1 (encoded by CCL2; Rainard et al., 2013). To our knowledge, only one previous study analyzed inflammatory responses during caloric restriction (Perkins et al., 2002). In that study circulating and mammary inflammatory markers were evaluated in mid-lactation cows after an intramammary LPS challenge. No differences were found in the inflammatory response between FR ( $80 \%$ of energy requirements) and AL-fed cows. In that published study and our current study, NEFA concentrations and NEB values were similar to those observed around parturition; however, the duration of NEB was shorter than what is observed in transition cows. Thus, to adequately evaluate the effect of lipolysis on inflammatory responses in AT or other organs using late lactation models of transition cow NEB, it may be necessary to extend caloric restriction interventions to several weeks in duration.

Lipolysis partly induces ATM infiltration by excessive release of fatty acids from adipocytes (Kosteli et al., 2010). Following migration into adipose, ATM uptake lipid as an adaptive response to excessive adipocyte lipolysis that prevents lipotoxicity at the adipose and systemic level (Prieur et al., 2011). In transition dairy cows, Akter et al. (2012) reported some ATM infiltration in OM and mesenteric AT of early lactation heifers, but not in SC AT. In that study, plasma NEFA and NEB were similar to those observed in our FR cows. In line with their findings, our results indicate ATM infiltration in OM adipose. Thus, in transition cows and during intense short lipolytic events, such as our caloric restriction model, lipolysis induces a mild ATM infiltration into adipose depots. Although a higher number of infiltrating ATM localized in aggregates were identified in FR cows, these cell conglomerates did not exhibit multinucleated cells or lipid remnants as was observed previously in transition cows with DA (Contreras et al., 2015). Furthermore, the number of ATM aggregates/100 adipocytes was below 1 compared with over 2 ATM aggregates/100 adipocytes in cows with DA (Contreras et al., 2015). These differences in the degree of ATM infiltration and aggregation may be related in part to the limited adipocyte turnover (i.e., apoptosis and necrosis) in FR cows that was reflected in the low expression of mitogenic genes. In monogastric species, adipocyte apoptosis and necrosis are important triggers of ATM aggregation and M1 polarization (Martinez-Santibañez and Nien-Kai Lumeng, 2014). The lower number of ATM aggregates in FR cows may also be linked to the relatively short duration of induced NEB (4 d). It is probable that longer periods of NEB increase the accumulation of lipolysis products in AT and further increase ATM aggregation over levels seen in this study. Identifying biomarkers of ATM ag- 
gregation in AT may provide a better assessment of AT metabolic function in transition dairy cows.

Lipolysis is also recognized as a modulator of ATM inflammatory phenotype. In rodents, extended periods of lipolysis polarize ATM toward a M1 (pro-inflammatory) phenotype (Kosteli et al., 2010). In transition dairy cows, we previously demonstrated that extended periods of NEB with high lipolytic rates associated with DA increase ATM populations and induce M1 phenotype polarization (Contreras et al., 2015). In our present study, however, cows in NEB did not exhibit increased expression of M1-related genes or cell surface proteins indicating changes in their inflammatory phenotype. Future studies should assess the effect of extended periods of lipolysis (several weeks) and also parturition-related physiological changes that are independent of lipolysis that may affect ATM infiltration and phenotype.

To our knowledge, this is the first study that evaluated gene expression of ECMT collagens (I and VI) and thrombospondin in AT from dairy cows during NEB. In humans and rodent models of insulin resistance, excessive deposition of these collagens in AT enhances macrophage infiltration (Khan et al., 2009; Divoux et al., 2010; Guglielmi et al., 2015). Also, in diabetic humans, collagen VI limits adipocyte expansion and therefore fatty acid uptake (Divoux et al., 2010). Our results indicate higher expression of both collagens in SC fat compared with OM fat during NEB. This finding highlights the differences in ECMT composition depending on the specific anatomical site of AT depots. It is possible that intense lipolysis for several weeks in the transition period may induce changes in the composition of ECMT that could impair AT function. Thus, determining the patterns of adipose ECMT change during the transition period may identify novel markers of AT function.

Our feed restriction protocol and interpretation of results have limitations. First, although we were able to mimic the lipolysis intensity observed around parturition, aspects of metabolic regulation critical to AT function are unique to the transition cow and cannot be mimicked by a restricted feeding model. For example, our feed restriction scheme did not emulate the duration of the lipolytic stimuli of transition dairy cows that may last up to 6 to 8 wk. It is possible that longer periods of intense lipolysis may have a more profound effect on AT remodeling features such as ATM infiltration and local inflammatory responses. A second limitation is that mid- and late-lactation cows adapt to NEB, not only by mobilizing lipid reserves from adipose, but also by reducing milk production. Although this mechanism reflects the differences in physiological profiles of transition and late-lactation cows, it provides a reductionist model where NEB-induced lipolysis is evaluated as a single factor in the modulation of AT remodeling.

\section{CONCLUSIONS}

Elevated rates of lipolysis during the transition period may lead to an acute AT remodeling process that could impair AT capacity for buffering excessive concentrations of circulating NEFA and therefore increase the risk for metabolic and inflammatory diseases. During severe NEB in transition cows with DA, AT remodeling is characterized by ATM infiltration and M1 polarization; however, the direct effect of lipolysis in NEB as a single physiological factor was unknown. Using a caloric restriction approach in late-lactation dairy cows that induced a NEB similar to that observed in transition dairy cows, we demonstrate for the first time that a 4-d intense lipolytic stimulus led to ATM infiltration in AT but with only minimal changes in inflammatory phenotype. These results underscore that physiological changes related to parturition and the onset of lactation or extended periods of lipolysis (or both) may induce intense AT remodeling with enhanced ATM inflammatory phenotype expression that may impair the metabolic function of AT in transition dairy cattle. Further studies are required to elucidate the dynamics of AT cellular and ECMT responses during AT remodeling in healthy transition dairy cows and the period of NEB required to impair the metabolic function of AT in dairy cattle.

\section{ACKNOWLEDGMENTS}

This project was supported in part by USDA-National Institute of Food and Agriculture (Washington, DC) grants 2014-68004-21972 and 2015-67015-23207, Department of Large Animal Clinical Sciences (East Lansing, MI), and the Michigan State University Elwood Kirkpatrick Dairy Science Research Endowment (East Lansing, MI). The authors are grateful to Connor Lewicki and Jeff Landgraf at the Michigan State University Genomic Research Technology Core Facility, and the staff at the Michigan State University Dairy Field Laboratory (East Lansing) for their technical assistance.

\section{REFERENCES}

Akbar, H., M. Bionaz, D. B. Carlson, S. L. Rodriguez-Zas, R. E. Everts, H. A. Lewin, J. K. Drackley, and J. J. Loor. 2013. Feed restriction, but not l-carnitine infusion, alters the liver transcriptome by inhibiting sterol synthesis and mitochondrial oxidative phosphorylation and increasing gluconeogenesis in mid-lactation dairy cows. J. Dairy Sci. 96:2201-2213.

Akter, S., S. Haussler, D. Germeroth, D. von Soosten, S. Danicke, K. H. Sudekum, and H. Sauerwein. 2012. Immunohistochemical char- 
acterization of phagocytic immune cell infiltration into different adipose tissue depots of dairy cows during early lactation. J. Dairy Sci. 95:3032-3044.

Ampem, G., H. Azegrouz, Á. Bacsadi, L. Balogh, S. Schmidt, J. Thuróczy, and T. Röszer. 2016. Adipose tissue macrophages in non-rodent mammals: A comparative study. Cell Tissue Res. $363: 461-478$

Arner, P., and D. Langin. 2014. Lipolysis in lipid turnover, cancer cachexia, and obesity-induced insulin resistance. Trends Endocrinol. Metab. 25:255-262.

Bjerre-Harpøth, V., N. C. Friggens, V. M. Thorup, T. Larsen, B. M. Damgaard, K. L. Ingvartsen, and K. M. Moyes. 2012. Metabolic and production profiles of dairy cows in response to decreased nutrient density to increase physiological imbalance at different stages of lactation. J. Dairy Sci. 95:2362-2380.

Boerman, J. P., S. B. Potts, M. J. VandeHaar, and A. L. Lock. 2015. Effects of partly replacing dietary starch with fiber and fat on milk production and energy partitioning. J. Dairy Sci. 98:7264-7276.

Choi, S. M., D. F. Tucker, D. N. Gross, R. M. Easton, L. M. DiPilato, A. S. Dean, B. R. Monks, and M. J. Birnbaum. 2010. Insulin regulates adipocyte lipolysis via an Akt-independent signaling pathway. Mol. Cell. Biol. 30:5009-5020.

Contreras, G. A., E. Kabara, J. Brester, L. Neuder, and M. Kiupel 2015. Macrophage infiltration in the omental and subcutaneous adipose tissues of dairy cows with displaced abomasum. J. Dairy Sci. 98:6176-6187

Contreras, G. A., Y.-H. Lee, E. P. Mottillo, and J. G. Granneman. 2014. Inducible brown adipocytes in subcutaneous inguinal white fat: The role of continuous sympathetic stimulation. Am. J. Physiol. Endocrinol. Metab. 307:E793-E799.

Contreras, G. A., N. J. O'Boyle, T. H. Herdt, and L. M. Sordillo. 2010 Lipomobilization in periparturient dairy cows influences the composition of plasma nonesterified fatty acids and leukocyte phospholipid fatty acids. J. Dairy Sci. 93:2508-2516.

De Koster, J. D., and G. Opsomer. 2013. Insulin resistance in dairy cows. Vet. Clin. North Am. Food Anim. Pract. 29:299-322.

Divoux, A., J. Tordjman, D. Lacasa, N. Veyrie, D. Hugol, A. Aissat, A. Basdevant, M. Guerre-Millo, C. Poitou, J.-D. Zucker, P. Bedossa, and K. Clément. 2010. Fibrosis in human adipose tissue: Composition, distribution, and link with lipid metabolism and fat mass loss. Diabetes 59:2817-2825.

Faylon, M. P., D. E. Koltes, and D. M. Spurlock. 2014. Regulation of lipid droplet-associated proteins following growth hormone administration and feed restriction in lactating Holstein cows. J. Dairy Sci. 97:2847-2855.

Ferrante, A. W. 2013. The immune cells in adipose tissue. Diabetes Obes. Metab. 15:34-38.

Ferraretto, L. F., H. Gencoglu, K. S. Hackbart, A. B. Nascimento, F. Dalla Costa, R. W. Bender, J. N. Guenther, R. D. Shaver, and M. C. Wiltbank. 2014. Effect of feed restriction on reproductive and metabolic hormones in dairy cows. J. Dairy Sci. 97:754-763.

Gross, J., H. A. van Dorland, R. M. Bruckmaier, and F. J. Schwarz. 2011a. Milk fatty acid profile related to energy balance in dairy cows. J. Dairy Res. 78:479-488.

Gross, J., H. A. van Dorland, R. M. Bruckmaier, and F. J. Schwarz. 2011b. Performance and metabolic profile of dairy cows during a lactational and deliberately induced negative energy balance with subsequent realimentation. J. Dairy Sci. 94:1820-1830.

Guglielmi, V., M. Cardellini, F. Cinti, F. Corgosinho, I. Cardolini, M. D'Adamo, M. C. Zingaretti, A. Bellia, D. Lauro, P. Gentileschi, M. Federici, S. Cinti, and P. Sbraccia. 2015. Omental adipose tissue fibrosis and insulin resistance in severe obesity. Nutr. Diabetes 5:e175.

Herdt, T. H. 2000. Ruminant adaptation to negative energy balance: Influences on the etiology of ketosis and fatty liver. Vet. Clin. North Am. Food Anim. Pract. 16:215-230.

Khan, M. J., A. Hosseini, S. Burrell, S. M. Rocco, J. P. McNamara, and J. J. Loor. 2013. Change in subcutaneous adipose tissue metabolism and gene network expression during the transition period in dairy cows, including differences due to sire genetic merit. J. Dairy Sci. 96:2171-2182.
Khan, T., E. S. Muise, P. Iyengar, Z. V. Wang, M. Chandalia, N. Abate, B. B. Zhang, P. Bonaldo, S. Chua, and P. E. Scherer. 2009 Metabolic dysregulation and adipose tissue fibrosis: Role of collagen VI. Mol. Cell. Biol. 29:1575-1591.

Koltes, D. A., and D. M. Spurlock. 2011. Coordination of lipid dropletassociated proteins during the transition period of Holstein dairy cows. J. Dairy Sci. 94:1839-1848.

Kosteli, A., E. Sugaru, G. Haemmerle, J. F. Martin, J. Lei, R. Zechner, and A. W. Ferrante Jr. 2010. Weight loss and lipolysis promote a dynamic immune response in murine adipose tissue. J. Clin. Invest. 120:3466-3479.

Lee, Y.-H., A. P. Petkova, and J. G. Granneman. 2013. Identification of an adipogenic niche for adipose tissue remodeling and restoration. Cell Metab. 18:355-367.

Mann, S., F. A. L. Yepes, T. R. Overton, J. J. Wakshlag, A. L. Lock, C. M. Ryan, and D. V. Nydam. 2015. Dry period plane of energy: Effects on feed intake, energy balance, milk production, and composition in transition dairy cows. J. Dairy Sci. 98:3366-3382.

Martinez-Santibañez, G., and C. Nien-Kai Lumeng. 2014. Macrophages and the regulation of adipose tissue remodeling. Annu. Rev. Nutr. 34:57-76.

Nielsen, N. I., K. L. Ingvartsen, and T. Larsen. 2003. Diurnal variation and the effect of feed restriction on plasma and milk metabolites in TMR-fed dairy cows. J. Vet. Med. A Physiol. Pathol. Clin. Med. 50:88-97.

NRC. 2001. Nutrient Requirements of Dairy Cattle. 7th rev. ed. Natl. Acad. Press, Washington, DC.

Oikawa, S., and G. R. Oetzel. 2006. Decreased insulin response in dairy cows following a four-day fast to induce hepatic lipidosis. J. Dairy Sci. 89:2999-3005

Ospina, P. A., J. A. McArt, T. R. Overton, T. Stokol, and D. V. Nydam. 2013. Using nonesterified fatty acids and $\beta$-hydroxybutyrate concentrations during the transition period for herd-level monitoring of increased risk of disease and decreased reproductive and milking performance. Vet. Clin. North Am. Food Anim. Pract. 29:387-412.

Palmquist, D. L., A. D. Beaulieu, and D. M. Barbano. 1993. Feed and animal factors influencing milk fat composition. J. Dairy Sci. 76:1753-1771.

Pasarica, M., B. Gowronska-Kozak, D. Burk, I. Remedios, D. Hymel, J. Gimble, E. Ravussin, G. A. Bray, and S. R. Smith. 2009. Adipose tissue collagen VI in obesity. J. Clin. Endocrinol. Metab. 94:5155-5162

Perkins, K. H., M. J. VandeHaar, J. L. Burton, J. S. Liesman, R. J. Erskine, and T. H. Elsasser. 2002. Clinical responses to intramammary endotoxin infusion in dairy cows subjected to feed restriction. J. Dairy Sci. 85:1724-1731.

Pires, J. A. A., L. F. Stumpf, I. D. Soutullo, J. B. Pescara, S. E. Stocks, and R. R. Grummer. 2016. Effects of abomasal infusion of nicotinic acid on responses to glucose and $\beta$-agonist challenges in underfed lactating cows. J. Dairy Sci. 99:2297-2307.

Prieur, X., C. Y. L. Mok, V. R. Velagapudi, V. Núñez, L. Fuentes, D. Montaner, K. Ishikawa, A. Camacho, N. Barbarroja, S. O'Rahilly, J. K. Sethi, J. Dopazo, M. Orešič, M. Ricote, and A. Vidal-Puig. 2011. Differential lipid partitioning between adipocytes and tissue macrophages modulates macrophage lipotoxicity and M2/M1 polarization in obese mice. Diabetes 60:797-809.

Pullen, D. L., D. L. Palmquist, and R. S. Emery. 1989. Effect on days of lactation and methionine hydroxy analog on incorporation of plasma fatty acids into plasma triglycerides. J. Dairy Sci. 72:49-58.

Rainard, P., P. Cunha, S. Bougarn, A. Fromageau, C. Rossignol, F. B. Gilbert, and P. Berthon. 2013. T Helper 17-associated cytokines are produced during antigen-specific inflammation in the mammary gland. PLoS One 8:e63471.

Reynolds, C. K., P. C. Aikman, B. Lupoli, D. J. Humphries, and D. E. Beever. 2003. Splanchnic metabolism of dairy cows during the transition from late gestation through early lactation. J. Dairy Sci. $86: 1201-1217$

Rutkowski, J. M., J. H. Stern, and P. E. Scherer. 2015. The cell biology of fat expansion. J. Cell Biol. 208:501-512. 
Sadri, H., R. M. Bruckmaier, H. R. Rahmani, G. R. Ghorbani, I. Morel, and H. A. Van Dorland. 2010. Gene expression of tumour necrosis factor and insulin signalling-related factors in subcutaneous adipose tissue during the dry period and in early lactation in dairy cows. J. Anim. Physiol. Anim. Nutr. (Berl.) 94:e194-e202.

Schmitt, E., M. A. Ballou, M. N. Correa, E. J. DePeters, J. K. Drackley, and J. J. Loor. 2011. Dietary lipid during the transition period to manipulate subcutaneous adipose tissue peroxisome proliferator-activated receptor- $\gamma$ co-regulator and target gene expression. J. Dairy Sci. 94:5913-5925.

Steibel, J. P., R. Poletto, P. M. Coussens, and G. J. M. Rosa. 2009. A powerful and flexible linear mixed model framework for the analysis of relative quantification RT-PCR data. Genomics 94:146-152.

Suganami, T., and Y. Ogawa. 2010. Adipose tissue macrophages: Their role in adipose tissue remodeling. J. Leukoc. Biol. 88:33-39.

van Knegsel, A. T. M., H. van den Brand, J. Dijkstra, W. M. van Straalen, M. J. W. Heetkamp, S. Tamminga, and B. Kemp. 2007.
Dietary energy source in dairy cows in early lactation: Energy partitioning and milk composition. J. Dairy Sci. 90:1467-1476.

Varma, V., A. Yao-Borengasser, A. M. Bodles, N. Rasouli, B. Phanavanh, G. T. Nolen, E. M. Kern, R. Nagarajan, H. J. Spencer, M.-J. Lee, S. K. Fried, R. E. McGehee, C. A. Peterson, and P. A. Kern. 2008. Thrombospondin-1 Is an adipokine associated with obesity adipose inflammation, and insulin resistance. Diabetes 57:432-439.

Velez, J. C., and S. S. Donkin. 2005. Feed restriction induces pyruvate carboxylase but not phosphoenolpyruvate carboxykinase in dairy cows. J. Dairy Sci. 88:2938-2948.

Verdes, J. M., L. Espino, A. Goicoa, L. Rigueira, L. A. Ramil, and L. E. Fidalgo. 2013. Quantification of pericaudal adipocyte diameter in dairy cattle during peripartum: A complementary method to study energetic status using conventional histology. J. Anim. Physiol. Anim. Nutr. (Berl.) 97:238-244. 